\title{
Effect of Irisin on Experimentally-Induced Preeclampsia in Female Albino Rats
}

\author{
REHAM H. IBRAHIM, M.D. and MARWA A. HABIB, M.D. \\ The Department of Physiology, Faculty of Medicine, Zagazig University, Egypt
}

\begin{abstract}
Background: Preeclampsia is a syndrome associated with pregnancy and characterized by new onset hypertension and proteinuria that might result from hypoxic placenta which secretes pathogenic factors that enter the maternal blood stream and result in endothelial dysfunction. Irisin is a myokine that improves endothelial dysfunction and has anti-oxidant and anti-inflammatory effects. Therefore, the current study aims to explore the possible effects of irisin on a model of preeclampsia induced experimentally in adult female albino rats and to explain the possible underlying mechanisms.
\end{abstract}

Material and Methods: 24 adult female albino rats were divided into three groups: Group I (control pregnant rats) That were injected daily with saline solution from 7 th day to 14th day of gestation, Group II (preeclamptic rats): In which pregnant rats were injected daily with L-NAME starting from the $7 \mathrm{t}^{\mathrm{h}}$ day to 14 th day of gestation, and Group III (irisintreated preeclamptic rats): In which L-NAME-induced preeclamptic rats were treated daily with intravenous irisin; $2 \mu \mathrm{g} / \mathrm{kg}$; from $10 \mathrm{t}^{\mathrm{h}}$ day to $19 \mathrm{t}^{\mathrm{h}}$ day of gestation. In all groups, systolic and diastolic Blood Pressure (BP), Total Urinary Proteins/24 hour (TUP), number of living pups and serum Endothelin-1 (ET-1), Interleukin-6 (IL-6), Nitric Oxide (NO), Placental Growth Factor (PGF), insulin, glucose, Super Oxide Dismutase (SOD), Malondialdehyde (MDA) were measured and HOMAIR was calculated.

Results: Irisin-treated preeclamptic rats showed significant decrease in systoilic BP, diastolic BP, TUP, ET-1, IL-6, HOMAIR, MDA and significant increase in the number of living pups, NO, PGF, SOD in comparison to preeclamptic rats.

Conclusion: Irisin may be a promising molecule for treatment of vascular complications of preeclampsia, as manifested by the improvement of hypertension and proteinuria in preeclamptic rats, through several mechanisms that may involve decreasing the oxidative stress, IL-6, ET-1 and insulin resistance or increasing the levels of PGF and NO.

Key Words: Irisin - Preeclampsia - Hypertension - Proteinuria - Placental ischemia.

Correspondence to: Dr. Reham H. Ibrahim, E-Mail: phisiology lover 4@yahoo.com

\section{Introduction}

PREECLAMPSIA is a disorder of pregnancy that starts after 20 weeks of pregnancy and characterized by high blood pressure and proteinuria, while; in severe cases; there may be hemolysis, thrombocytopenia, liver dysfunction, kidney dysfunction, edema, dyspnea due to fluid in the lungs, or visual disturbances and if left untreated, it may result in seizures known as eclampsia [1]. The pathogenesis of preeclampsia was suggested to be due to decreased delivery of blood to the developing uteroplacental unit resulting in hypoxia and oxidative stress that release into the maternal circulation substances such as free radicals, oxidized lipids, and cytokines [2] leading to endothelial disturbance [3] with vascular hyper permeability, hypertension and inflammation [2].

Irisin is a 112 amino acids polypeptide hormone secreted as a product of fibronectin type III domain containing 5 (FNDC5) from skeletal muscle in mice, rats and humans [4]. Numerous studies highlighted the beneficial and protective properties of irisin level elevation in insulin resistance, obesity and metabolic disturbance [5-7]. The study by Garcés et al., demonstrated that irisin precursor protein (FNDC5) is expressed in decidual, cytotrophoblast and syncytiotrophoblast in human placenta of normal pregnancy. Also, they found higher irisin levels in middle and late pregnancy compared with early pregnancy in healthy women suggesting that placenta might be a source of increased serum irisin levels during normal pregnancy [8].

There are contradictory reports about serum profile of irisin in preeclamptic pregnancy. While it was reported that there is a decrease in serum irisin levels in preeclampsia patients [8], on the other hand, Zhanga et al., did not find any change in serum irisin levels in preeclamptic patients [9] 
It is worth saying that irisin was reported to have vasodilator [10], antioxidant [11,12], anti inflammatory effects $[\mathbf{1 3 , 1 4}]$ and to improve endothelial dysfunction [15], which suggest that it may aid in improvement of placental ischemia during preeclamp sia.

Therefore, the aims of the current study were to explore the possible effects of irisin on a model of preeclampsia induced in adult female albino rats and to explain the possible involved mechanisms.

\section{Material and Methods}

In the period from 15 th February to 10 th May 2017, the study was performed in the Animal House of Faculty of Medicine, Zagazig University and involved twenty four healthy adult female albino rats and four adult male albino rats of local strain weighing 170-190g and aged 12-16 weeks that were obtained from the Animal House, Faculty of Veterinary Medicine, Zagazig University. All rats were kept in steel wire cages under high hygienic conditions, had free access to water and kept on standard diet which consisted of mixed commercial rat laboratory chow $(25.88 \%$ protein, $62.98 \%$ carbohydrate and $11.94 \%$ fat) [16]. Rats were kept at comfortable temperature, maintained on natural light/dark cycle [17] and accommodated to laboratory conditions for three weeks before starting the experiments [18]. All experimental procedures were conducted in accordance with the guiding principles for the care and use of research animals and were approved by the Institutional Research Board.

\section{Grouping of animals:}

The male rats were used for induction of pregnancy. The female rats were divided into three equal groups: Group I (control pregnant rats): That were injected daily with saline solution at a dose of $0.5 \mathrm{ml} / 100 \mathrm{~g}$ Body Weight (BW) subcutaneously starting from the 7 th day to 14 th day of gestation, Group II (preeclamptic rats): That were injected daily with nitric oxide synthase inhibitor; [NGnitro-L-arginine methyl ester, L-NAME, (SigmaAldrich, U.S.A.)] at a dose of $10 \mathrm{mg} / 0.5 \mathrm{ml} \mathrm{sa}-$ line/100g BW subcutaneously starting from the $7^{\text {th }}$ day to 14 th day of gestation to induce an animal model of preeclampsia [19], Group III (irisin-treated preeclamptic rats): That were injected daily with L-NAME at a dose of $10 \mathrm{mg} / 0.5 \mathrm{ml}$ saline $/ 100 \mathrm{~g} \mathrm{BW}$ subcutaneously from the 7 th day to 14 th day of gestation [19] and treated daily with irisin (SigmaAldrich, U.S.A.) at a dose of $2 \mu \mathrm{g} / \mathrm{kg} \mathrm{BW}$ intravenously [20] starting from the 10 th day to 19 th day of gestation [21].

\section{Methods:}

Determination of the first day of pregnancy: By vaginal smears which were examined daily by using light microscope to ensure the regularity of estrus cycle. The female proved to be in estrus phase; established by the presence of cornified epithelial cells in vaginal smears [22]; was paired with a mature male rat in a separate cage. After mating, females were subsequently isolated until the time of analysis to ensure accurate gestation timing, and in the next morning a vaginal smear taken. Copulation was confirmed by the presence of a copulation plug or spermatozoa in the vagina which indicated the first day of gestation [23].

Urine collection: The $24 \mathrm{~h}$-urine samples were collected at the 19 th day of pregnancy. The rats were housed individually in metabolic cages and urine was collected at the bottom of the cages in suitable-sized funnels with plastic perforated discs to retain fecal matter [24]. The urine sample for each rat was collected in a beaker placed under the funnel and centrifuged for 10 minutes at 3000 $\mathrm{rpm}$. The supernatants were transferred into another set of clean and dry tubes and stored at $-20^{\circ} \mathrm{C}$ until analysis.

Measurement of Blood Pressure (BP): Systolic and diastolic BP were measured in all studied groups at the 20 th day of pregnancy. The rats were anesthetized with urethane (1.2g/kg, i.p.) [25] and the trachea was cannulated by polyethylene tube. The invasive (direct) blood pressure was measured by cannulation of the carotid artery by a polyethylene catheter filled with heparinized saline connected to physiological pressure transducer of Power Lab data acquisition system [26]

Blood sampling: At the 20th day of pregnancy, blood samples were taken from retro orbital vessels under ether anesthesia between 9-11A.M. with animals overnight fasting. The blood was collected in clean plastic centrifuge tubes and allowed to clot. Serum was separated by centrifugation of blood at 3000rpm for 15 minutes [27]. The supernatant serum was pipetted off using fine tipped automatic pipettes and stored frozen at $-20^{\circ} \mathrm{C}$ until used.

Estimation of the number of living pups: At the 20th day of pregnancy, after blood pressure measurement, pups were delivered by cesarean section; the number of living pups was recorded.

\section{Estimations:}

Total urinary proteins: By using Microlab 300 (Vital Scientific, Germany), according to the man- 
ufacturer's protocol through the principle of turbidimetry using 5\% trichloroacetic acid [28]. Serum Endothelin-1 level (ET-1): By using a doubleantibody sandwich ELISA rat ET-1 kits according to Khraibi et al., [29]. Serum Interleukin 6 (IL-6) level: By using a double-antibody sandwich ELISA rat IL-6 kits according to Song et al., [30]. Serum Nitric Oxide (NO) level: Was estimated as nitrite, a NO metabolite, by monitoring of reduction of $\mathrm{NO}_{3}{ }^{-}$to $\mathrm{NO}_{2}{ }^{-}$by nitrate reductase or metallic catalyst, then $\mathrm{NO}_{2}{ }^{-}$levels (nitrite levels) were measured using the calorimetric Griess Reaction [31].Serum Placental Growth Factor (PGF) level: By using quantitative sandwich ELISA PGF Kits (Marburg, Germany) according to Cowans et al., [32].Serum insulin level: By using KAP1251-INSEASIA (Enzyme Amplified Sensitivity Immunoassay) Kits (BioSource Europe S.A., Belgium) according to Temple et al., [33]. Serum glucose level: by using enzymatic (GOD-PAP)-liquizyme glucose kits (Biotechnology, Egypt), according to Tietz [34]. HOMA-IR: Was calculated by homeostasis model assessment [where HOMA = Fasting serum insulin ( $(\mathrm{mmol} / \mathrm{L}) / 22.5$ ] according to Matthews et al., [35] Serum Super Oxide Dismutase (SOD) level: By a modified spectrophotometric assay using Bio diagnostic, Egypt kits according to Kakker et al., [36]. Serum Malondialdehyde (MDA) level: ${ }^{\text {By }}$ a spectrophotometeric assay using Bio diagnostic, Egypt kits according to Metkari et al., [37].

\section{Statistical analysis:}

The data obtained in the present study were expressed as mean \pm SD for quantitative variables and statistically analyzed by using SPSS program (Version 18 for windows) (SPSS Inc. Chicago, IL, USA). One way analysis of variance (ANOVA) was done followed by LSD test to compare means of the different groups. $p$-value $<0.05$ was considered statistically significant.

\section{Results}

Table (1) shows the effect of irisin administration on all measured parameters in the three studied groups. There was a significant increase in the Systolic Blood Pressure (SBP) in Group II (preeclamptic rats; $p<0.001$ ) and Group III (irisin-treated preeclamptic rats; $p<0.001)$ when compared to that of Group I (control pregnant rats); while, there was a significant decrease in SBP in Group III $(p<0.001)$ when compared to that of Group II. Additionally, there was a significant increase in the Diastolic Blood Pressure (DBP) in Group II $(p<0.001)$ in comparison to Group I; while, in Group III, there was a significant decrease in DBP when compared to that of Group II $(p<0.001)$ and no significant change when compared to that of Group I ( $p>0.05$ ). Regarding the Total Urine Proteins (TUP), there was a significant increase in Group II $(p<0.001)$ and Group III $(p<0.001)$ when compared to that of Group I; while there was a significant decrease in TUP in Group III when compared to that of Group II $(p<0.001)$.

Regarding the number of living pups, it was significantly decreased in Group II when compared to that of Group I $(p<0.001)$. However, it was significantly increased in Group III when compared to that of Group II $(p<0.01)$, and significantly decreased when compared to that of Group I $\left(p<^{\mathrm{O}, 01}\right)$.

As regard the Placental Growth Factor (PGF), it was significantly decreased in Group II when compared to that of Group I $(p<0.001)$. However, it was significantly increased in Group III when compared to that of Group I and Group II $(p<0.001)$.

Concerning Nitric Oxide (NO), it was significantly decreased in Group II when compared to that of Group I ( $p<0.001)$. While in Group III, no was significantly increased when compared to that of Group I and Group II $(p<0.001)$.

As regard Malonaldehyde (MDA), there was a significant increase in Group II when compared to that of Group I $(p<0.01)$. However in Group III, there was a significant increase when compared to that of Group I $(p<0.01)$ and significant decrease when compared to that of Group II $(p<0.01)$. Concerning superoxide dismutase (SOD), it was significantly decreased in Group II when compared to that of Group I $(p<0.001)$. While in Group III, SOD was significantly decreased when compared to that of Group I ( $p<0.001)$ and significantly increased when compared to that of Group II $(p<0.001)$.

Regarding Endothelin 1 (ET-1), there was a significant increase in group II when compared to that of Group I $(p<0.001)$. However in Group III, ET-1 was significantly increased when compared to that of Group I $(p<0.001)$ and significantly decreased when compared to that of Group II $(p<0.01)$. Concerning Interleukin-6 (IL-6), it was significantly increased in Group II when compared to that of Group I $(p<0.001)$. While in Group III, IL-6 was significantly increased when compared to that of Group I ( $p<0.001)$ and significantly decreased when compared to that of Group II.

Regarding Insulin, there was a significant increase in Group II when compared to that of Group 
I ( $p<0.001)$. However in Group III, there was no significant change in serum insulin when compared to that of Group I ( $p>0.05)$ and a significant decrease when compared to that of Group II $(p<0.01)$. As regard HOMA-IR, it was significantly increased in Group II when compared to that of Group I $(p<0.001)$. While in Group III, HOMA-IR was significantly increased when compared to that of Group I $(p<0.01)$, and significantly decreased when compared to that of Group II $(p<0.001)$.

Table (1): Effect of irisin administration on all measured parameters in all studied groups.

\begin{tabular}{|c|c|c|c|}
\hline Parameters & $\begin{array}{c}\text { Group I } \\
\text { (control } \\
\text { pregnant rats) }\end{array}$ & $\begin{array}{l}\text { Group II } \\
\text { (preeclamptic } \\
\text { rats) }\end{array}$ & $\begin{array}{c}\text { Group III } \\
\text { (irisin-treated } \\
\text { preeclamptic rats) }\end{array}$ \\
\hline Systolic BP (mmHg) & $102.4 \pm 0.34$ & $145.49 \pm 2.98^{\mathbf{a}}$ & $120.6 \pm 1.35^{\mathbf{a}} \mathbf{b}$ \\
\hline Diastolic BP (mmHg) & $81.9 \pm 11.3$ & $112 \pm 8.6^{\mathbf{a}}$ & $85 \pm 4.2^{\mathbf{b}}$ \\
\hline Total urine protein $(\mathrm{mg} / \mathrm{L})$ & $5.3 \pm 0.07$ & $13.9 \pm 0.83^{\mathrm{a}}$ & $8.02 \pm 0.91 \mathbf{a}, \mathbf{b}$ \\
\hline Number of living pubs & $11 \pm 2.1$ & $5 \pm 1.5^{\mathrm{a}}$ & $8 \pm 1.3^{\mathbf{a}} \mathbf{b}$ \\
\hline Placental growth factor $(\mathrm{pg} / \mathrm{mL})$ & $60.3 \pm 12.6$ & $23 \pm 11.2^{\mathrm{a}}$ & $85 \pm 13.2^{\mathbf{a}^{\mathbf{a}} \mathbf{b}}$ \\
\hline Nitric oxide $(\mathbf{m}-/ \mathrm{L})$ & $68.89 \pm 14.01$ & $37.55 \pm 26.611^{a}$ & $107.10 \pm 14.74^{\mathbf{a}^{\prime} \mathbf{b}}$ \\
\hline Malonaldehyde (mollL) & $2.3 \pm 0.3$ & $4.9 \pm 0.4^{\mathrm{a}}$ & $3.5 \pm 0.6^{\mathbf{a} \cdot \mathbf{b}}$ \\
\hline Superoxide dismutase $(\mathrm{mg} / \mathrm{dl})$ & $140.15 \pm 8.8$ & $83 \pm 7.23^{\mathrm{a}}$ & $125 \pm 9.9^{\mathbf{a}^{\prime} \mathbf{b}}$ \\
\hline Endothelin-1 (pg/ml) & $1.67 \pm 0.20$ & $4.56 \pm 0.30^{\mathrm{a}}$ & $3.9 \pm 18.7^{\mathbf{a} \cdot \mathbf{b}}$ \\
\hline Interleukin-6 (pg/ml) & $30 \pm 0.2$ & $70 \pm 0.3^{\mathbf{a}}$ & $43 \pm 5.2^{\mathbf{a} \cdot \mathbf{b}}$ \\
\hline Insulin (mIU/L) & $8.50 \pm 0.70$ & $13.50 \pm 0.80^{\mathbf{a}}$ & $9.2 \pm 2.48^{\mathbf{b}}$ \\
\hline HOMA-IR & $2.60 \pm 0.24$ & $4.90 \pm 0.21 \mathrm{a}$ & $3.2 \pm 1.21^{\mathbf{a}^{\prime} \mathbf{b}}$ \\
\hline
\end{tabular}

Data are expressed as mean $\pm \mathrm{SD}$.

(a): Significant vs. Group I.

(b): Significant vs. Group II.

\section{Discussion}

In the current study, a model of experimental preeclampsia in adult female albino rats was performed. The occurrence of preeclampsia was confirmed by the statistically significant elevation in blood pressure and the total urine proteins in comparison to control pregnant rats. These findings are in line with another study that specified hypertension and proteinuria as diagnostic criteria for preeclampsia [38]. In the current study we used the nitric oxide synthase inhibitor (L-NAME) for induction of preeclampsia in pregnant rats as chronic Nitric Oxide Synthase (NOS) inhibition in pregnant rats produced a pattern similar to preeclampsia such as hypertension, proteinuria, intrauterine retarded growth, and increased fetal morbidity [39]

The present study also studied the effect of treating preeclamptic rats with intravenous irisin and found that irisin significantly improved the signs of preeclampsia as evidenced by the significant reduction in both systolic and diastolic blood pressure and the total urinary proteins and the significant increase in the number of living pups in comparison to the preeclamptic rats. The present study suggested that reduction in irisin levels might play a part in the pathogenesis of preeclampsia and that treatment with irisin can compensate for this reduction and improve preeclampsia-associated complications. In support of this suggestion, Garcés et al., reported that serum levels of irisin were reduced in preeclamptic patients and suggested that low irisin levels might be involved in the pathogenesis of the disease. Also, they suggested that the low levels during the first and second trimesters might be a good predictor of the development of the disease [8]. Moreover, it was reported that FNDC5 placental expression was upregulated and positively correlated with systolic blood pressure and urinary protein levels in preeclamptic patients; while; serum irisin level was found to be negatively associated with systolic and diastolic blood pressure levels; which propose that irisin might play a role in regulation of blood pressure [9].

The present study tried to explain the possible involved mechanisms through which irisin improved the signs of preeclampsia. Placental Growth Factor (PGF) is a member of the vascular endothelial growth factor sub-family secreted from placental trophoblast that was reported to play a role in trophoblast growth and differentiation and was considered as an important member in vasculogenesis, in particular during embryogenesis [40] and also essential in the maintenance of proper endothelial cell function and health [39]. In the current study, we found that serum levels of PGF were significantly decreased in preeeclamptic rats in relation to control pregnant rats. Consistent with our findings, it was reported that serum levels of 
PGF were reduced in women presenting with both early and late onset preeclampsia, and this reduction was considered to be responsible for the endothelial dysfunction that produced hypertension and the glomerular endothelial injury that produced proteinuria [41]. The present study found a significant increase in serum levels of PGF in preeclamptic rats treated with irisin in comparison to those of preeclamptic rats. So, it was suggested that irisin may be an effective treatment for the endothelial dysfunction produced by reduced PGF in preelampsia.

No was suggested to have an important role in modulating arterial pressure [39]. The elevation of no production in normal pregnancy was suggested to play an important role in the vasodilatation that occurs in pregnancy [42]. In the present study, treating preeclamptic rats with irisin caused a significant increase in serum no levels in comparison to those of preeclamptic rats. Consistent with our finding, Han et al., reported that irisin could stimulate no production in human umbilical vascular endothelial cells [10]. In addition, Fu et al., reported that irisin increased no production, whereas pretreatment with L-NAME abolished the stimulatory effect of irisin on no production [43]. Moreover, it was reported that irisin enhances the phosphorylation of AMPK that has been characterized as an energy sensor (sensitive to the AMP/ATP ratio) in the regulation of glucose uptake and fatty acid oxidation in the whole body [44]. AMPK was reported to induce phosphorylation of eNOS and to activate no generation in endothelial cells [43]

Oxidative stress has also been implicated in preeclampsia. In the present study, we found a state of oxidative stress in preeclamptic rats that was evidenced by increased serum levels of Malonaldehyde (MDA) and decreased serum levels of Superoxide Dismutase (SOD) in comparison to control pregnant rats. In agreement with our results, increased concentrations of several oxidative stress markers were found in preeclamptic women concurrent with decreased levels of SOD [45]. Moreover, NADPH oxidase inhibitor; apocynin; was reported to attenuate placental ischemia-induced gestational hypertension, implicating the enzyme as an important source of pathogenic free radicles [39]. In the current study, preeclamptic rats treated with irisin showed reduced oxidative stress state that was proved by the significant reduction in serum levels of MDA and the increase in serum levels of SOD in comparison to preeclamptic rats. In line with our finding, irisin was suggested to have antioxidant role as it was reported to increase the expression of antioxidant enzymes, inhibit oxidative stress of vascular endothelial cells and down-regulate NADPH oxidase $[\mathbf{1 1 , 1 2}$. So, the current study suggested that irisin may be a promising myokine for treatment of vascular complications of preeclampsia caused by oxidative stress.

There is a growing evidence suggesting an important role for the potent endothelium-derived vasoconstrictor; Endothelin-1 (ET-1) in the pathophysiology of preeclampsia. Our study found a significant increase in serum ET-1 levels in preeclamptic rats compared with control pregnant rats. In accordance with our findings, elevated levels of plasma ET-1 were reported in preeclamptic women [46]. Moreover, George and Granger reported that hypertension in preeclamptic rats was attenuated by ETA receptor antagonism, and they suggested that ET-1 might be a final common pathway linking factors produced during placental ischemia to elevations in blood pressure [46]. In the current study, treating preeclamptic rats with irisin significantly reduced serum ET-1 levels compared with those of preeclamptic rats. This effect may be due to the reducing effect of irisin on IL-6 which is a strong stimulator of endothelin secretion [47].

Failure of maternal immune tolerance was also suggested to be involved in the pathophysiology of preeclampsia as it might induce poor placentation and impaired placental perfusion and chronic immune activation originating from the placenta [48]

Also, it might share in the exaggerated inflammatory response in preeclampsia with excessive production of Interleukin 6 (IL-6), Tumor Necrosis Factor (TNF) and Monocyte Chemoattractant Protein 1 (MCP-1) [49]. These reports support the present study findings that revealed a significant increase in serum levels of IL-6 in preeclamptic rats compared with control pregnant rats. The present study found a significant decrease in serum IL-6 levels in preeclamptic rats treated with irisin compared with preeclamptic rats. This finding is in line with many studies which suggested that irisin has anti-inflammatory properties $[13,14,50,51]$ The High-Mobility Group Box 1 protein (HMGB 1) is a nuclear DNA-binding protein which can be actively secreted by stimulated macrophages, or passively by damaged or necrotic cells [52]. Also, HMGB 1 was reported to induce an activation of NF-B [53] and consequently enhances secretion of pro-inflammatory factors, including TNF [54]. Irisin was reported to inhibit the expression and release of HMGB 1 and consequently reduce the expression and release of pro-inflammatory cytokines, such as TNF, IL-6, MCP-1 [55]. 
Insulin resistance has also been involved in the pathogenesis of preeclampsia. In the current study, we observed increased insulin resistance; as indicated by the rise in HOMA-IR levels; in preeclamptic rats in relation to control pregnant rats. Consistent with our findings, it was reported that insulin resistance was increased in women with established preeclampsia relative to normal pregnancy [56]. Moreover, it was demonstrated that diminished insulin-mediated activation of NOS resulted in decreased nitric oxide production and led to reduced vasodilatation [57]. This reduced vasodilatatory effect of insulin was suggested to induce a small increase in peripheral resistance leading to hypertension [58]. In the current study, treating preeclamptic rats with irisin was found to increase insulin sensitivity as indicated by the significant reduction in HOMA-IR levels in comparison to those of preeclamptic rats. The present study suggested that the reduction in blood pressure in irisin-treated preeclamptic rats may be attributed to irisin-induced rise in insulin sensitivity which improved the reduced vasodilatatory effect of insulin in preeclamptic rats. This finding is in line with other studies which demonstrated that irisin improved glucose tolerance and reduced fasting insulin, and therefore, improved insulin sensitivity [59].

It is worth saying that irisin may improve preeclampsia still through other mechanisms. It was reported that irisin enhanced protein levels of Heme Oxygenase-1 (HO-1); the stress response gene that is considered a cytoprotective pathway counteracting pathophysiological insults during pregnancy [15]. HO-1 activation was suggested to inhibit the expression of oxidative-stress-induced adhesion molecules [60]. While, human HO-l deficiency was reported to attenuate the cytoprotective effect of NO [61], and to induce severe and persistent endothelial damage in preeclampsia [62].

Moreover, it was reported that irisin potently promoted angiogenesis via increasing formation of capillary-like structures by increasing protein and mRNA expression and activity of Matrix Metalloproteinases (MMPs) [63] . Specifically, MMP2 and MMP-9 were found to be involved in remodeling of placental and uterine arteries [64] and abnormal expression of these MMPs has been found in hypertensive disorders of pregnancy [65]

\section{Conclusion:}

This study provides the first evidence that irisin may be a promising treatment for preeclampsiaassociated vascular complications as manifested by the improvement of hypertension and proteinuria in preeclamptic rats. Several mechanisms might be implicated in the effect of irisin in preeclamptic rats which may be through decreasing oxidative stress, IL-6, ET-1 and insulin resistance or through increasing PGF and NO. Further studies are recommended for demonstrating the irisin effects in preeclamptic women and the accurate underlying mechanisms.

\section{References}

1- AL-JAMEIL N., AZIZ KHAN F., FAREED KHAN M. and TABASSUM H.: A brief overview of preeclampsia. J. Clinic. Med. Resear., 6 (1): 1-7, 2014.

2- BRAMHAM.K., PARNELL B., NELSON-PIERCY C., SEED P.T., POSTON L. and CHAPPELL L.C.: Chronic hypertension and pregnancy outcomes: Systematic review and meta-analysis. B.M.J., 348: g2301, 2014.

3- ROBERTS J.M.: Endothelial dysfunction in preeclampsia. Semin. Reprod. Endocrinol., 16: 5-15, 1998.

4- BOSTROM P., WU J. and JEDRYCHOWSKI M.P.: A pgc1-alpha-dependent myokine that drives brown-fat-like development of white fat and thermogenesis. Nat., 481: 463-8, 2012.

5- LOPEZ-LEGARREA P., De LA IGLESIA R., CRUJEIRAS A.B., PARDO M., CASANUEVA F.F., ZULET M.A. and MARTINEZ J.A.: Higher baseline irisin concentrations are associated with greater reductions in glycemia and insulinemia after weight loss in obese subjects. Nutr. Diabetes, 4: e110, 2014.

6- CHEN J.Q., HUANG Y.Y., GUSDON A.M. and QU S.: Irisin: A new molecular marker and target in metabolic disorder. Lipids Health Dis., 14 (1): 2-5, 2015.

7- SHI X., LIN M., LIU C., XIAO F., LIU Y., HUANG P., ZENG X., YAN B., LIU S., LI X. and YANG S.: Elevated circulating irisin is associated with lower risk of insulin resistance: Association and path analyses of obese Chinese adults. B.M.C. Endocr. Disord., 16 (1): 44, 2016.

8- GARCÉS M.F., PERALTA J.J. and RUIZ-LINARES C.E.: Irisin levels during pregnancy and changes associated with the development of pre-eclampsia. J. Clin. Endocrinol. Metab., 99: 2113-9, 2014.

9- ZHANGA L.J., XIEA Q., TANGB C.S. and ZHANG A.H.: Expressions of irisin and urotensin II and their relationships with blood pressure in patients with preeclampsia. Clin. Exp. hypertens., 39 (5): 460-7, 2017.

10- HAN F., ZHANG S., HOU N., WANG D. and SUN X.: Irisin improves endothelial function in obese mice through the AMPK-eNOS pathway. Am. J. Physiol. Heart Circ. Physiol., 309: 1501-8, 2015.

11-LU J., XIANG G., LIU M., MEI W. and XIANG L.: Irisin protects against endothelial injury and ameliorates atherosclerosis in apolipoprotein E-Null diabetic mice. Atherosclerosis, 243 (2): 438-8, 2015.

12- ZHU D., WANG H., ZHANG J., ZHANG X. and XIN C.: Irisin improves endothelial function in type 2 diabetes through reducing oxidative/nitrative stresses. J. Mol. cell Cardiol., 87: 138-47, 2015. 
13- LI D.J., LI Y.H., YUAN H.B. and QU L.F.: The novel exercise-induced hormone irisin protects against neuronal injury via activation of the Akt and ERK1/2 signaling pathways and contributes to the neuroprotection of physical exercise in cerebral ischemia. Metabolism, 68: 31-42, 2017.

14- VAUGHAN R.A., GANNON N.P., MERMIER C.M. and CONN C.A.: Irisin, a unique non-inflammatory myokine in stimulating skeletal muscle metabolism. J. Physiol. Biochem., 71 (4): 679-89, 2015.

15- HOU N., LIU Y., HAN F. and WANG D.: Irisin improves perivascular adipose tissue dysfunction via regulation of the heme oxygenase-1/adiponectin axis in diet-induced obese mice. J. Mol. Cell Cardiol., 99: 188-96, 2016.

16- AHREN B. and SCHEURINK A.J.W.: Marked hyperleptinemia after high-fat diet associated with severe glucose intolerance in mice. Eur. J. Endocrinol., 139: 461-7, 1998.

17- LESOURD B. and MAZARI L.: Nutrition and immunity in the elderly. Proc. Nutr. Soc., 58: 685-95, 1999.

18- GUI Y., SILHA J.V. and MURPHY L.J.: Sexual Dimorphism and Regulation of Resistin, Adiponectin, and Leptin Expression in the Mouse. Obesity, 12 (9): 1481-91, 2004.

19- CURTIS N.E., GUDE N.M., KING R.G. and MARRIOTT P.J.: Nitric Oxide Metabolites in Normal Human Pregnancy and Preeclampsia. Hypertens. Pregnancy, 14: 339-49, 1995.

20- ZHANG W., CHANG L., ZHANG C., ZHANG R., LI Z., CHAI B., LI J., CHEN E. and MULHOLLAND M.: Central and peripheral irisin differentially regulate blood pressure. Cardiovasc. Drugs Ther., 29: 121-7, 2015.

21- SHINYAMA H., YAMANAGA K., AKIRA T., UCHIDA T., YAGUCHI M., WATANABE M. and KAGITANI Y.: Antithrombin III Prevents Blood Pressure Elevation and Proteinuria Induced by High Salt Intake in Pregnant Stroke-Prone Spontaneously Hypertensive Rats. Biol. Pharm. Bull., 19: 819-23, 1996.

22- BARCELONA R.S., FANELLI O. and CAMPANA A.: Teratological study in the rabbit and rat. Teratology, 2: 87-94, 1977.

23- KLUKOVITS A., GÁSPÁR R., SÁNTHA P., JANCSÓ G. and FALKAY G.: Functional and histochemical characterization of a uterine adrenergic denervation process in pregnant rats. Biol. Reprod., 67: 1013-7, 2002.

24- PERLINE I.R.: An inexpensive mouse urine collection system. Physiol. Behav., 6 (5): 597, 1971.

25- MILLER F.N. and WIEGMAN D.L.: Anesthesia-induced alteration of small vessel responses to norepinephrine. Eur. J. Pharmacol., 44 (4): 331-7, 1977.

26- BACHHAV S.S., BHUTADA M.S., PATIL S.P., SHARMA K.S. and PATIL S.D.: Oleanolic acid prevents increase in blood pressure and nephrotoxicity in nitric oxide dependent type of hypertension in rats. Pharmacognosy Res., 7 (4): 385-92, 2015.

27- YANG S., BINGYANG J. and UNDAR A.: Microfluidic Devices for Continuous Blood Plasma Separation and Analysis During Pediatric Cardiopulmonary Bypass Procedures. J. ASAIO, 52: 698-704, 2006.

28- DILENA B.A., PENBERTHY L.A. and FRASER C.G.:
Six methods for determining urinary protein compared. Clin. Chem., 29: 553-7, 1983.

29- KHRAIBI A., HEUBLEIN D.M. and KNOX F.G.: Increased Plasma Level of Endothelin-1 in the Okamoto Spontaneously Hypertensive Rat. Mayo Clinic Proc., 68: 42-6, 1993.

30- SONG C., DINAN T. and LEONARD B.E.: Changes in immuno-globulin complement and acute phase protein levels in the depressed patients and normal controls. J. Affect Disord., 30: 283-8, 1994.

31- IGNARRO L.J., FUKUTO J.M., GRISCAVAGE J.M., ROGERS N.E. and BYRNS R.E.: Oxidation of nitric oxide in aqueous solution to nitrite but not nitrate: Comparison with enzymatically formed nitric oxide from Larginine. Proc. Natl. Acad. Sci. U.S.A., 90: 8103-7, 1993.

32- COWANS N.J., STAMATOPOULOU A. and MATWEJEW E.: First-trimester placental growth factor as a marker for hypertensive disorders. Prenat. Diagn., 30 (6): 565-70, 2010.

33- TEMPLE R.C., CLARK P.M. and HALES C.N.: Measurement of insulin secretion in type 2 diabetes: Problems and pitfalls. Diabet. Med., 9: 503-12, 1992.

34- TIETZ N.W.: Clinical guide to laboratory tests, 3 rd ED. W.B. Saunders, Co., Philadelphia, pp. 509-12, 1995.

35- MATTHEWS D.R., HOSKER J.P., RUDENSKI A.S. and NAYLOR B.A.: Homeostasis model assessment: Insulin resistance and beta-cell function from fasting plasma glucose and insulin concentrations in man. Diabetologia, 28 (7): 412-9, 1985.

36- KAKKAR P., DAS B. and VISWANATHAN P.N.: A modified spectrophotometric assay of superoxide dismutase. Indian J. Biochem. Biophys., 21: 130-2, 1984.

37- METKARI S.B., TUPKARI J.V. and BARPANDE S.R.: An estimation of serum malondialdehyde, superoxide dismutase and vitamin $\mathrm{A}$ in oral submucous fibrosis and its clinicopathologic correlation. J. Oral Maxillofac. Pathol., 11 (1): 23-7, 2007.

38- FUKUI A., YOKOTA M., FUNAMIZU A. and NAKAMUA R.: Changes of NK cells in preeclampsia. Am. J. Reprod. Immunol., 67: 278-86, 2012.

39- GILBERT J.S., RYAN M.J., LAMARCA B.B., SEDEEK M., MURPHY S.R. and GRANGER J.P.: Pathophysiology of hypertension during preeclampsia: Linking placental ischemia with endothelial dysfunction. Am. J. Physiol. Heart Circ. Physiol., 294: 541-50, 2008.

40- KHALIL A., MUTTUKRISHNA S., HARRINGTON K., JAUNIAUX E. and LUMBIGANON P.: Effect of antihypertensive therapy with alpha methyldopa on levels of angiogenic factors in pregnancies with hypertensive disorders. PloS One, 3 (7): 2766, 2008.

41- GERMAIN S.J., SACKS G.P., SOORANNA S.R. and SARGENT I.L.: Systemic inflammatory priming in normal pregnancy and preeclampsia: The role of circulating syncytiotrophoblast microparticles. J. Immunol., 178: 5949-56, 2007.

42- CONRAD K.P., KERCHNER L.J. and MOSHER M.D.: Plasma and 24-h NO(x) and cGMP during normal pregnancy and preeclampsia in women on a reduced $\mathrm{NO}(\mathrm{x})$ diet. Am. J. Physiol., 277: 48-57, 1999. 
43- FU J., HAN Y., WANG J., LIU Y., ZHENG S., ZHOU L., JOSE P.A. and ZENG C.: Irisin Lowers Blood Pressure by Improvement of Endothelial Dysfunction via AMPKAkt-eNOS-NO Pathway in the Spontaneously Hypertensive Rat. J. Am. Heart Assoc., 5 (11): e003433, 2016.

44- CARLING D. and VIOLLET B.: Beyond energy homeostasis: The expanding role of AMP-activated protein kinase in regulating metabolism. Cell Metab., 21: 799804, 2015.

45- HUNG T.H. and BURTON G.J.: Hypoxia and reoxygenation: a possible mechanism for placental oxidative stress in preeclampsia. Taiwan J. Obstet. Gynecol., 45: 189200, 2006.

46- GEORGE E.M. and GRANGER J.P.: Endothelin: Key mediator of hypertension in preeclampsia. Am. J. Hypertens., 24: 964-9, 2011.

47- ZHOU C.C., IRANI R.A. and DAI Y.: AutoantibodyMediated IL-6-Dependent Endothelin-1 Elevation Underlies Pathogenesis in a Mouse Model of Preeclampsia. J. Immunol., 186 (10): 6024-34, 2011.

48- REDMAN C.W. and SARGENT I.L.: Immunology of Pre-Eclampsia. A.J.R.I., 63 (6): 534-43, 2010.

49- CATARINO C., SANTOS-SILVA A. and BELO L.: Inflammatory Disturbances in Preeclampsia: Relationship between Maternal and Umbilical Cord Blood. J. Pregnancy, 2012: 684384, 2012

50- POLYZOS S.A., KOUNTOURAS J., ANASTASILAKIS A.D., GELADARI E.V. and MANTZOROS C.S.: Irisin in patients with nonalcoholic fatty liver disease. Metabol., 63: 207-17, 2014

51- DONG J., DONG Y., CHEN F., MITCH W.E. and ZHANG L.: Inhibition of myostatin in mice improves insulin sensitivity via irisin-mediated cross talk between muscle and adipose tissues. Int. J. Obes., 40: 434-42, 2016.

52- STROS M.: HMGB proteins: Interactions with DNA and chromatin. Biochim. Biophys. Acta., 1799: 101-13, 2010.

53- YOUN J.H., OH Y.J. and KIM E.S.: High mobility group box 1 protein binding to lipopolysaccharide facilitates transfer of lipopolysaccharide to CD14 and enhances lipopolysaccharide-mediated TNF-alpha production in human monocytes. J. Immunol., 180: 5067-74, 2008.

54- EL-GAZZAR M.: HMGB 1 modulates inflammatory responses in LPS-activated macrophages. Inflamm. Res., 56: 162-7, 2007.
55- MAZUR-BIALY A.I., POCHEC E. and ZARAWSKI M. Anti-Inflammatory Properties of Irisin, Mediator of Physical Activity, Are Connected with TLR4/MyD88 Signaling Pathway Activation. Int. J. Mol. Sci., 18 (4): E701, 2017.

56- SEELY E.W. and SOLOMON C.G.: Insulin resistance and its potential role in pregnancy-induced hypertension. J. Clin. Endocrinol. Metab., 88: 2393-8, 2003.

57- CHIANG H.T., CHENG W.H. and LU P.J.: Neuronal Nitric Oxide Synthase Activation Is Involved in InsulinMediated Cardiovascular Effects in the Nucleus Tractus Solitarii of Rats. Neuroscience, 159 (2): 727-34, 2009.

58- O'ROURKE M.: Mechanical principles in arterial disease. Hypertens., 26: 2-9, 1993.

59- GAMAS L., MATAFOME P. and SEIÇA R.: Irisin and Myonectin Regulation in the Insulin Resistant Muscle: Implications to Adipose Tissue: Muscle Crosstalk. J. Diabetes Res., 2015: 359159, 2015.

60- XIAOHAN J., ZHONGWEI X. and RONG F.: HO 1 alleviates cholesterol induced oxidative stress through activation of Nrf2/ERK and inhibition of PI3K/AKT pathways in endothelial cells. Mol. Med. Rep., 6962: 3519-27, 2017.

61- POLTE T., OBERLE S. and SCHRODER H.: Nitric oxide protects endothelial cells from tumor necrosis factoralpha-mediated cytotoxicity: Possible involvement of cyclic GMP. FEBS Lett., 409 (1): 46-8, 1997.

62- PALMA C.A., ZAMORA C. and GONZÁLEZ M.A.: Human chorionic gonadotropin upregulates heme oxygenase-1 (HO-1). Is the (GT)n HMOX-1 polymorphism relevant in preeclampsia? Placenta, 36 (4): 483, 2015.

63- WU F., SONG H., ZHANG Y., ZHANG Y., MU Q. and JIANG M.: Irisin Induces Angiogenesis in Human Umbilical Vein Endothelial Cells In Vitro and in Zebrafish Embryos In Vivo via Activation of the ERK Signaling Pathway. PLoS ONE, 10 (8): e0134662, 2015.

64- ISAKA K., USUDA S. and ITO H.: Expression and activity of matrix metalloproteinase 2 and 9 in human trophoblasts. Placenta, 24: 53-64, 2003.

65- LALU M.M., XU H. and DAVIDGE S.T.: Matrix metalloproteinases: Control of vascular function and their potential role in preeclampsia. Front. Biosci., 12: 248493, 2007. 


\section{تآثير الإيرسين على تسمم الحمل المحددث تجريبيا في إناث الجرذان البيضاء}

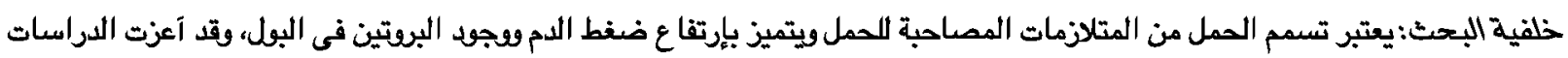

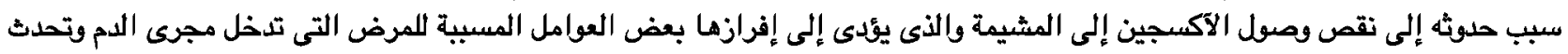

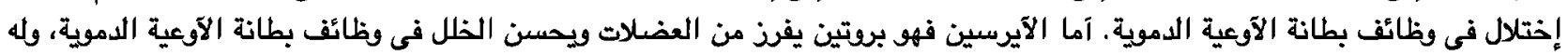
تآثير كمضاد للإلتهابات ومضاد للآكسدة.

الهدف من البحث: تهدف هذه الدراسة إلى إستكثاف التآثير المحتمل للآيرسين على نموذج تسمم الحمل المحدث تجريبيا فى إناث الجرذان البيضاء البالغة، وشرح الآليات المحتملة لهذا التهر التَّير.

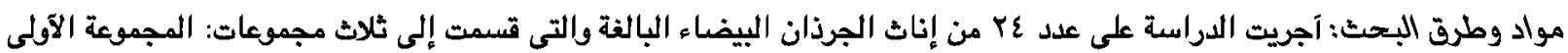

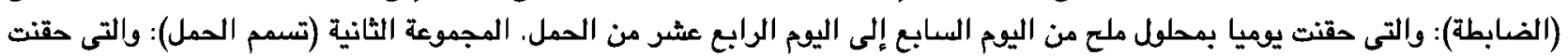

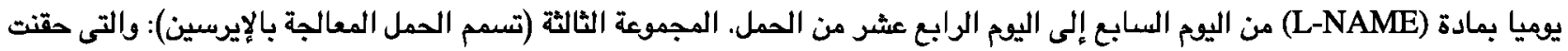

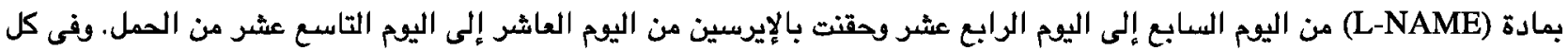

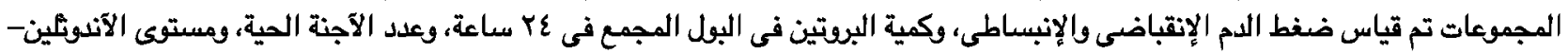

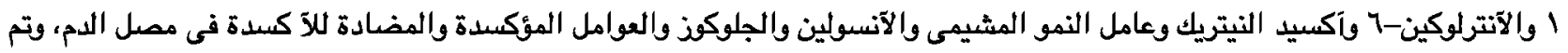
حساب معامل مقاومة الآنسولين.

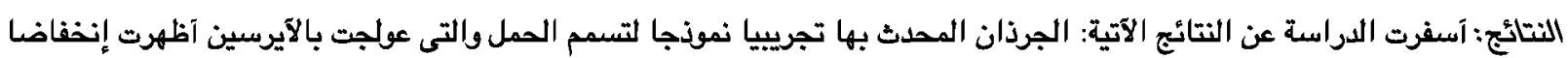

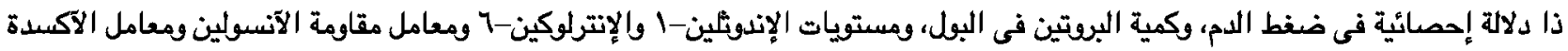

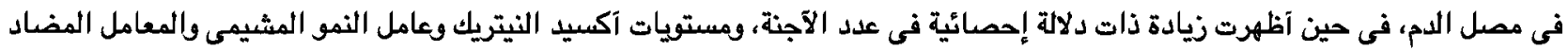

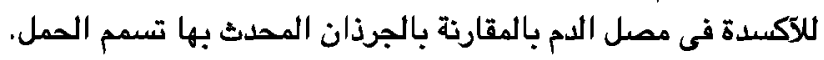

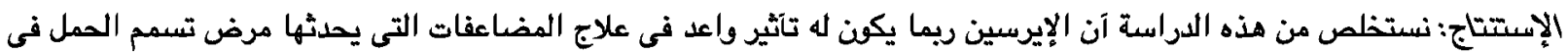
الآوعية الدموية من خلال عدة آليات قد تنطوى على خفض الإنس الإكسدة ومستويات الإندوثلين-ا والإنترلوكين-7 ومقاومة الآنسولين، آوزيادة مستويات عامل النمو المشيمى وآكسيد النيتريك. 